\title{
Preferential Effects of the Metabotropic Glutamate 2/3 Receptor Agonist LY379268 on Conditioned Reinstatement versus Primary Reinforcement: Comparison between Cocaine and a Potent Conventional Reinforcer
}

\author{
Marco A. S. Baptista, Rémi Martin-Fardon, and Friedbert Weiss \\ Department of Neuropharmacology, The Scripps Research Institute, La Jolla, California 92037
}

\begin{abstract}
Metabotropic glutamate receptors (mGluRs) have been implicated in regulating anxiety, stress responses, and the neurobehavioral effects of psychostimulants. The present study sought to determine whether group II mGluR activation by the potent mGlu2/3 receptor agonist, (-)-2-oxa-4-aminobicylco hexane-4,6-dicarboxylic acid (LY379268), antagonizes reinstatement of cocaine-seeking induced by cocaine-related stimuli and whether this effect extends to behavior induced by stimuli conditioned to a potent conventional reinforcer, sweetened condensed milk (SCM). Also, we tested whether the suppressant effects of LY379268 on conditioned reinstatement extend to the primary reinforcing effects of cocaine or SCM. Rats were trained to associate discriminative stimuli $\left(S^{\mathrm{D}}\right)$ with the availability of cocaine or SCM versus non-reward and then subjected to repeated extinction sessions during which the respective reinforcers and $S^{\mathrm{D}}$ were withheld. Subsequent reexposure to the cocaine or SCM S ${ }^{\mathrm{D}}$, but not the non-reward $\mathrm{S}^{\mathrm{D}}$, produced recovery of responding at the previously active lever. LY379268 $(0.3-3.0 \mathrm{mg} / \mathrm{kg}$, s.c.) dose-dependently attenuated recovery of cocaine seeking but reduced conditioned reinstatement by the SCM S ${ }^{\mathrm{D}}$ only at the highest dose. LY379268 did not alter responding reinforced directly by SCM, and only the highest LY379268 dose reduced cocaine self-administration. The results suggest that the effects of LY379268 are selective for behavior maintained by cocaine as opposed to palatable conventional reinforcers. More importantly, the results show that LY379268 suppresses behavior motivated by stimuli conditioned to cocaine or SCM more effectively than consummatory behavior maintained by the unconditioned effects of these substances. As such, the results identify group II mGluRs as a pharmacotherapeutic target for craving and relapse prevention associated with cocaine cue exposure.
\end{abstract}

Key words: addiction; self-administration; drug-seeking behavior; relapse; drug cues; group II mGluRs

\section{Introduction}

Group II metabotropic glutamate receptors (mGluRs) have been implicated in presynaptic negative modulation of excitatory glutamate and inhibitory GABA transmission (Schoepp, 2001). Agonists for the group II (mGlu2/3) receptors have been found to inhibit damage to CA1 hippocampal neurons induced by global ischemia (Bond et al., 2000), to diminish haloperidol-induced muscle rigidity in an animal model of Parkinson's disease (Konieczny et al., 1998), to attenuate enhanced auditory startle responses after nicotine withdrawal (Helton et al., 1997), and to reduce fear potentiated startle in an animal model of anxiety (Helton et al., 1998). Recently, the potent mGlu2/3 agonist, (-)-2-oxa-4-aminobicylco hexane-

\footnotetext{
Received Jan. 16, 2004; revised March 25, 2004; accepted April 12, 2004.

This is publication number 15898-NP from the Scripps Research Institute. This research was supported by National Institutes of Health-National Institute on Drug Abuse Grants DA07348 and DA08467 (F.W). We thank Nate Stuempfig and Jeff Simms for excellent technical assistance and Mike Arends for assistance with the preparation of this manuscript. We gratefully acknowledge Drs. H. C. Fibiger and D. D. Schoepp (Lilly Research Laboratories) for providing LY379268.

Correspondence should be addressed to Marco A. S. Baptista, 10550 North Torrey Pines Road, CVN 15, La Jolla, CA 92037. E-mail: bmarco@scripps.edu

DOI:10.1523/JNEUROSCI.0176-04.2004

Copyright $\odot 2004$ Society for Neuroscience $\quad$ 0270-6474/04/244723-05\$15.00/0
}

4,6-dicarboxylic acid (LY379268), was shown to attenuate both acute and sensitized motor behaviors induced by phencyclidine (PCP) and amphetamine (Cartmell et al., 2000a,b; Clark et al., 2002; Kim and Vezina, 2002). The interference with locomotor sensitization by LY379268 indicates that mGlu2/3 receptors may play a role in psychostimulant addiction, including drug craving and vulnerability to relapse (Kim and Vezina, 2002).

One consequence of psychostimulant-induced sensitization is dysregulation of glutamatergic neurotransmission ( $\mathrm{Xi}$ et al., 2002). Chronic psychostimulant exposure has been implicated in relapse risk associated with drug-related environmental stimuli and drug reexposure "priming," as well as in panic reactions and psychosis (Wolf, 1998; Cornish et al., 1999; Berke and Hyman, 2000; Ungless et al., 2001). Persistent vulnerability to relapse presents a considerable challenge for the treatment of drug addiction. Repeated cocaine treatments can alter the function of group I and II mGluRs in the nucleus accumbens (Nac) (Xi et al., 2002), pointing toward a possible role of these mGluR types in susceptibility to relapse. Focusing on group II receptors, it was of interest to determine whether the previously reported reversal of psychostimulant-induced locomotor behavior and sensitization resulting from pharmacological activation of this receptor (Cart- 
mell et al., 2000a,b; Clark et al., 2002; Kim and Vezina, 2002) extends to interference with the reinforcing effects of cocaine. Specifically, the present experiments sought to characterize and compare the effects of the mGlu2/3 receptor agonist LY379268 on two pivotal aspects of the addictive potential of cocaine: (1) the conditioned effects of the drug as manifested by the responsereinstatement actions of drug-related environmental stimuli, and (2) the unconditioned effects of the drug in rats intravenously self-administering cocaine. A complementary objective was to compare and contrast the effects of LY379268 on cocaine-related behaviors with its effects on conditioned and unconditioned behaviors motivated by a potent conventional reinforcer, sweetened condensed milk (SCM).

\section{Materials and Methods}

Animals

Forty-eight male Wistar rats (Charles River, Wilmington, MA) weighing 200-250 gm on arrival were housed in groups of three in a $12 \mathrm{hr}$ light/ dark cycle (lights off at 6:00 P.M.) vivarium. Rats had ad libitum access to food and water except during acquisition of food-reinforced operant responding at the beginning of the cocaine self-administration training procedure. Behavioral training and testing were conducted during the light phase of the light/dark cycle at the same time each day. All procedures were conducted in strict adherence to the National Institutes of Health Guide for the Care and Use of Laboratory Animals.

\section{Drugs}

Cocaine hydrochloride (National Institute on Drug Abuse, Bethesda, MD) was dissolved in sterile physiological saline. The $\mathrm{mGlu} 2 / 3$ receptor agonist LY379268 (Lilly Research Laboratories, Indianapolis, IN) was dissolved in sterile water.

\section{Self-administration, conditioning, and test procedures}

Cocaine. Rats were food restricted for $24 \mathrm{hr}$ and allowed to lever press for $45 \mathrm{mg}$ food pellet reinforcers (Research Diets) to facilitate later acquisition of operant responding maintained by intravenous cocaine. Once rats had earned 100 pellets, they were returned to ad libitum feeding and surgically prepared with chronic SILASTIC catheter implants in the right jugular vein under isoflurane $(1.0-1.5 \%)$ anesthesia as described previously (Caine and Koob, 1993). Ten days after surgery, cocaine selfadministration training began in daily $2 \mathrm{hr}$ sessions conducted $5 \mathrm{~d}$ per week for a total of $10 \mathrm{~d}$. Sessions were initiated by extension of two retractable levers into the operant conditioning chamber. Responses at the right, active lever were reinforced on a fixed-ratio 1 (FR1) schedule by an injection of cocaine $(0.25 \mathrm{mg} / 0.1 \mathrm{ml}$, i.v. $)$ infused over a period of 4 sec. Each reinforced response was followed by a $20 \mathrm{sec}$ time-out (TO) period, signaled by illumination of a cue light above the right lever. During this time, the lever remained inactive to prevent accidental overdosing. Responses at the left, inactive lever had no scheduled consequences. Catheter patency was maintained by flushing with $0.1 \mathrm{ml}$ of sterile heparin/saline (33.3 USP U/ml) solution before and after each session.

Effect of LY379268 on cocaine self-administration. Rats $(n=7)$ designated for tests of the effects of LY379268 on the acute reinforcing effects of cocaine continued to receive daily access to the drug until they maintained stable cocaine intake ( $\pm 10 \%$ over three consecutive sessions). Once this acquisition criterion was reached, drug testing began. Thirty minutes before test sessions, rats were injected with LY379268 $(0.0,0.3$, 1.0 , or $3.0 \mathrm{mg} / \mathrm{kg}$, s.c.) and then received access to cocaine for $2 \mathrm{hr}$. Each animal was tested once with each LY379268 dose according to a withinsubjects design, with the drug doses administered using a Latin square design. Between each drug test, self-administration sessions were conducted in the absence of LY379268 or vehicle treatments until stable cocaine intake as defined above was reconfirmed.

Effect of LY379268 on conditioned reinstatement. After acquisition of stable cocaine-reinforced responding, rats $(n=7)$ designated for tests of LY379268 effects on conditioned reinstatement continued to receive daily access to cocaine, but under a reinforcement contingency in which responses at the active lever were differentially reinforced in the presence of distinct discriminative stimuli $\left(\mathrm{S}^{\mathrm{D}}\right)$ as described previously (Weiss et al., 2001). Briefly, a $70 \mathrm{~dB}$ constant white noise signaled the availability of cocaine, serving as an $\mathrm{S}^{+}$, whereas the house light signaled availability of saline solution (i.e., non-reward), serving as an $\mathrm{S}^{-}$. Under these contingencies, two drug sessions and one non-reward session, separated by 30 min, were conducted in random order on each training day. Between sessions, rats were placed in their home cages for $30 \mathrm{~min}$. Drug and saline sessions lasted $1 \mathrm{hr}$ each and were initiated by presentation of the respective $S^{D}$ and extension of the levers. The respective $S^{D}$ remained present until termination of the session by retraction of the levers. All other self-administration procedures remained identical to those described above.

After completion of 30 conditioning sessions, rats were placed on extinction conditions. During this phase, $1 \mathrm{hr}$ sessions began by extension of the levers without $S^{\mathrm{D}}$ presentation. Responses at the previously active lever activated the syringe pump motor but did not produce intravenous infusions. Extinction sessions were conducted once daily until a criterion of four or fewer responses per session over 3 consecutive days was reached.

Two days after the $\mathrm{S}^{-}$session, tests of the effects of LY379268 on conditioned reinstatement in the presence of the $\mathrm{S}^{+}$began. LY379268 $(0.0,0.3,1.0$, or $3.0 \mathrm{mg} / \mathrm{kg}$, s.c.) was administered $30 \mathrm{~min}$ before reinstatement sessions. Each rat was tested once with each dose of LY379268 according to a within-subjects design, with drug doses administered using a Latin square design. Rats were treated with LY379268 (or vehicle) on days $4,10,16$, and 22 of the reinstatement phase. On days 7, 13, 19, and 25 , rats were tested without drug or vehicle treatment to confirm that the number of reinstatement responses produced by the $\mathrm{S}^{+}$remained stable over time under "no-treatment" conditions. Test sessions were separated by a $2 \mathrm{~d}$ period during which rats remained in their home cages.

\section{$S C M$}

SCM-reinforced responding was established in 40 min sessions conducted $5 \mathrm{~d}$ /week for $30 \mathrm{~d}$. SCM (two parts water/one part SCM) was available on the same FR1,TO20 contingency used for cocaine selfadministration. Each lever press was reinforced by $0.1 \mathrm{ml}$ of SCM delivered into a dispenser over a $4 \mathrm{sec}$ period. Daily SCM sessions were conducted until rats maintained stable levels of responding $( \pm 10 \%$ over three consecutive sessions).

Effect of LY379268 on SCM reinforcement. Rats $(n=6)$ designated for test of LY379268 effects on SCM-reinforced responding were tested using the same within-subjects design, experimental protocol, and LY379268 doses as in the cocaine self-administration tests above, except that test sessions lasted only $40 \mathrm{~min}$.

Effect of LY379268 on conditioned reinstatement. After acquisition of stable SCM-reinforced responding, rats $(n=28)$ designated for tests of LY379268 effects on conditioned reinstatement were subjected to the same conditioning procedures as described for cocaine selfadministering rats, with the following exceptions: (1) to avoid satiety by excessive ingestion of SCM, each of the three daily conditioning sessions lasted only $20 \mathrm{~min}$, and (2) during non-reward sessions, signaled by the $\mathrm{S}^{-}$, no "vehicle" solution was available and responses remained without consequence. After completion of 30 conditioning sessions, rats were placed on extinction conditions. These sessions lasted $1 \mathrm{hr}$ and were identical in all aspects to those described above for cocaine selfadministering rats.

One day after reaching the extinction criterion, testing for conditioned reinstatement and its modification by LY379268 began in $1 \mathrm{hr}$ sessions. All experimental procedures were identical to those used for the test of conditioned cocaine reinstatement above with one exception. Previous findings suggest that the response-reinstating effects of SCM-associated cues extinguish rapidly when repeated reinstatement tests are conducted (Martin-Fardon et al., 2003). Therefore, a between-subjects design was used such that each rat was tested with each LY3792678 dose (or vehicle) only once. All tests for effects of LY379268 on S ${ }^{+}$-induced reinstatement were conducted $2 \mathrm{~d}$ after an initial $\mathrm{S}^{-}$session to verify that recovery of responding is selectively controlled by SCM-associated $\mathrm{S}^{\mathrm{D}}$. 

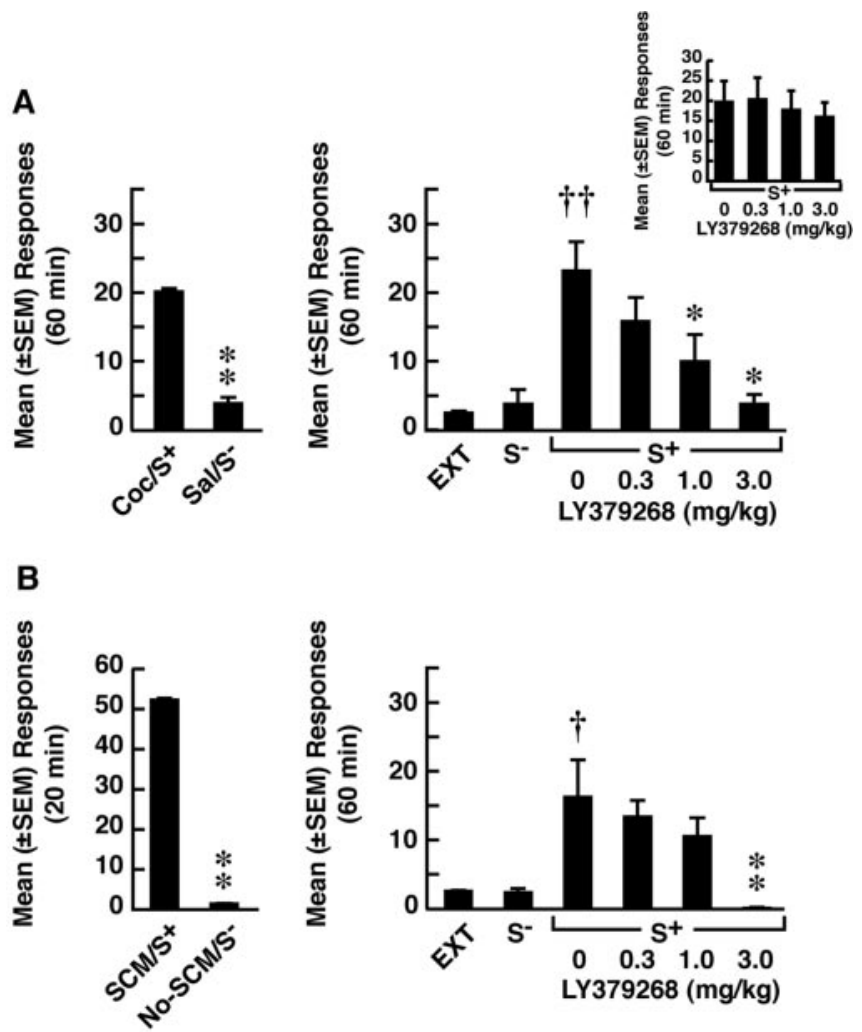

Figure 1. Effects of $L Y 379268$ on reinstatement induced by discriminative stimuli associated with cocaine or SCM. $A$, Responses during cocaine $\left(\mathrm{Coc} / \mathrm{S}^{+}\right)$and saline $\left(\mathrm{Sal} / \mathrm{S}^{-}\right)$selfadministration, extinction, (EXT), reinstatement tests in the presence of the saline $\left(S^{-}\right)$versus cocaine $\left(S^{+}\right)$cues, and LY379268 effects on conditioned reinstatement ${ }^{* *} p<0.0001$ vs $S^{+}$; ${ }^{{ }^{+\dagger}} p<0.001$ vs $S^{-}$and EXT; ${ }^{*} p<0.05$ vs vehicle). Inset, Reinstatement responses without drug or vehicle treatment $2 \mathrm{~d}$ after each drug test. $B$, Responses during SCM self-administration $\left(\mathrm{SCM} / \mathrm{S}^{+}\right.$) versus non-reward (no-SCM/S ${ }^{-}$) sessions, extinction (EXT), reinstatement tests in the presence of the non-reward $\left(S^{-}\right)$versus SCM $\left(S^{+}\right)$cues, and effects of $L Y 379268$ on conditioned reinstatement $\left({ }^{* *} p<0.0001\right.$ vs SCM $/ S^{+} ;{ }^{\dagger} p<0.05$ vs $S^{-}$and EXT; ${ }^{* *} p<0.001$ vs vehicle).

\section{Results}

Conditioned reinstatement: cocaine

No differences were observed in the mean number of cocainereinforced responses across the last $3 \mathrm{~d}$ of the self-administration and conditioning phase, and between the first and second daily hour of cocaine availability. Therefore, the data of the two daily cocaine sessions were pooled for analysis. Responding during cocaine availability differed significantly $\left(F_{(1,6)}=139.24 ; p<\right.$ 0.0001 ) from that during saline availability (Fig. $1 A$ ). After initiation of the extinction contingency, the rats required $7.1 \pm 2$ sessions on average to reach the criterion. The mean ( \pm SEM) number of responses per session during the last $3 \mathrm{~d}$ of the extinction phase was $2.6 \pm 0.32$ (Fig. $1 A$ ).

During subsequent reinstatement testing, responses remained at extinction levels when rats were presented with the non-reward (saline-associated) $\mathrm{S}^{-}$(Fig. 1A). In contrast, exposure to the cocaine $\mathrm{S}^{+}$(after vehicle treatment) elicited recovery of responding: $F_{(2,6)}=20.9 ; p<0.0001$. Newman-Keuls post hoc tests revealed that this effect was significant against both the extinction $(p<0.05)$ and $\mathrm{S}^{-}$conditions $(p<0.05)$.

Effect of LY379268 on conditioned reinstatement (cocaine) LY379268 dose-dependently decreased the recovery of responding induced by the cocaine $\mathrm{S}^{+}$, reflected by a significant main effect for drug doses $\left(F_{(3,6)}=5.36 ; p<0.05\right)$. Post hoc analysis by Newman-Keuls tests revealed that LY379268 significantly $(p<$ 0.05 ) attenuated reinstatement at the 1.0 and $3.0 \mathrm{mg} / \mathrm{kg}$ doses (Fig. 1A). Reinstatement of $\mathrm{S}^{+}$-induced cocaine seeking in the absence of drug treatments remained stable between tests (Fig. $1 A$, inset).

\section{Conditioned reinstatement: SCM}

No differences in the mean number of SCM-reinforced responses were observed during the last $3 \mathrm{~d}$ of the training and conditioning phase and between the first and second daily SCM availability. The data of the two daily SCM sessions were therefore pooled for subsequent analysis. Responding during SCM availability differed significantly $\left(F_{(1,27)}=4191.42 ; p<0.0001\right)$ from that during non-reward sessions (Fig. $1 B$ ). Rats required $11.3 \pm 1.4$ (mean \pm SEM) sessions to reach the extinction criterion. The mean $( \pm$ SEM) number of responses across the last $3 \mathrm{~d}$ of the extinction phase was $2.6 \pm 0.19$ (Fig. $1 B$ ).

During reinstatement tests, responses remained at extinction levels in rats tested with the non-reward $\mathrm{S}^{-}$(Fig. $1 B$ ). Subsequent exposure to the SCM S ${ }^{+}$(after vehicle treatment) elicited strong recovery of responding $\left(F_{(2,6)}=5.80 ; p<0.05\right)$. Newman-Keuls post hoc tests confirmed that this effect was significantly different against the extinction $(p<0.05)$ and $S^{-}$conditions $(p<0.05)$. In contrast to the effects of the cocaine $\mathrm{S}^{+}$that produced responding indistinguishable from cocaine-reinforced responses during the training phase (Fig. $1 A$ ), reinstatement responses elicited by the $\mathrm{SCM} \mathrm{S}^{+}$remained significantly below the number of SCM-reinforced responses during the training phase (Fig. $1 B$ ). Nonetheless, the number of $\mathrm{S}^{+}$-induced responses (in vehicletreated rats) did not differ statistically between the cocaine and SCM groups.

\section{Effect of LY379268 on conditioned reinstatement (SCM)}

As shown in Figure $1 \mathrm{~B}$, LY379268 attenuated responding induced by the SCM S${ }^{+}$compared with vehicle-treated rats $\left(F_{(3,24)}=4.63 ; p<0.01\right)$; however, this effect was significant $(p<0.05)$ only for the highest dose $(3.0 \mathrm{mg} / \mathrm{kg})$ of LY379268 (Newman-Keuls).

\section{Effect of LY379268 on the primary reinforcing effects of cocaine and SCM \\ Cocaine}

All animals acquired stable self-administration levels after 10 training days. LY379268 decreased the number of cocainereinforced responses $\left(F_{(3,6)}=19.26\right.$; $\left.p<0.0001\right)$ (Fig. $\left.2 A\right)$, however, with significant $(p<0.05)$ effects only at the $3.0 \mathrm{mg} / \mathrm{kg}$ dose (Newman-Keuls).

\section{SCM}

All rats reached stable SCM intake after 10 d. LY379268 did not alter responding for SCM at any dose (Fig. 2 B).

\section{Discussion}

LY379268 effectively and dose-dependently reversed conditioned reinstatement induced by the cocaine $\mathrm{S}^{+}$but was less potent in altering the primary reinforcing effects of cocaine and reduced self-administration of the psychostimulant only at the highest dose. Compared with its effects on conditioned reinstatement by the cocaine $\mathrm{S}^{+}$, LY379268 was less effective in attenuating behavior elicited by the SCM S ${ }^{+}$, with significant effects at the highest dose only. LY379268 failed to alter SCM intake at any dose and thus proved ineffective in reducing behavior main- 

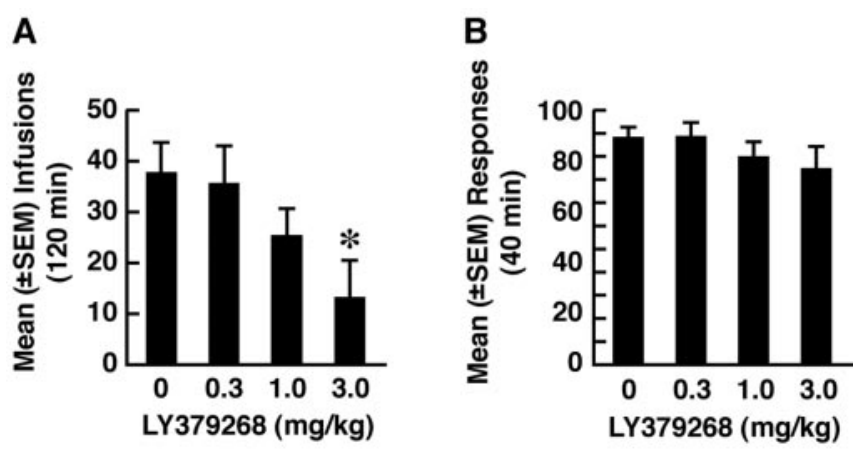

Figure 2. Effects of $L Y 379268$ on cocaine and SCM self-administration. $A$, Number of cocaine infusions after vehicle versus LY379268 administration ( ${ }^{*} p<0.05$ vs $0,0.3$, and $1.0 \mathrm{mg} / \mathrm{kg}$ ). $B$, SCM-reinforced responses after vehicle versus LY379268 administration. Responding was not attenuated by LY379268 treatments.

tained by this highly potent conventional reinforcer. These observations suggest that $\mathrm{mGlu} 2 / 3$ receptor activation by LY379268 exerts inhibitory effects on goal-directed behavior that, overall, appear more selective for responses induced by stimuli conditioned to drug or non-drug reinforcers than for behavior maintained by the respective primary reinforcers. Moreover, with respect to effects on primary reinforcement, the results suggest that $\mathrm{mGlu} 2 / 3$ receptor activation selectively attenuates the rewarding effects of cocaine as opposed to those of conventional reinforcers.

The lack of effects of LY379268 on the high rates of responding maintained by SCM suggests that the attenuation of conditioned reinstatement and cocaine self-administration by this mGlu2/3 agonist cannot be attributed to motor impairments. This interpretation is supported also by previous reports showing that LY379268, at the same doses as in the present study, blocks the locomotor stimulant effects of PCP and amphetamine but does not induce motor deficits as measured in rotorod and ataxia tests (Cartmell et al., 1999, 2000b).

\section{Effects on conditioned cocaine reinstatement versus cocaine self-administration}

One hypothesis as to why LY379268 proved more selective in attenuating conditioned reinstatement than the acute reinforcing effects of cocaine is that this mGlu2/3 agonist may be differentially effective in modulating dopamine (DA) release in the basolateral amygdala (BLA) versus the Nac. Cocaine cues increase DA release in both the BLA and the Nac (Ito et al., 2000; Weiss et al., 2000) and elevate extracellular glutamate levels in the Nac (Hotsenpiller et al., 2001). Group II mGluRs function as glutamate autoreceptors, and stimulation of $\mathrm{mGlu} 2 / 3$ reduces presynaptic and glial glutamate release by inhibiting $\mathrm{N}$-type calcium channels (Xi et al., 2002) and the cystine-glutamate antiporter (Xi et al., 2002; Baker et al., 2003). By lowering extracellular glutamate, activation of mGlu2/3 receptors also reduces extracellular DA (Wigmore and Lacey, 1998). Extracellular DA concentrations produced by cocaine self-administration are approximately twofold higher in the Nac than in the amygdala (Hurd et al., 1997) and in both brain regions are considerably higher than DA levels associated with exposure to cocaine cues. Thus, it is likely that only high doses of LY379268 effectively lower the high extracellular DA levels in the Nac during cocaine self-administration and thereby interfere with the reinforcing efficacy of cocaine. In contrast, lower doses of LY379268 may be sufficient to reverse the mild elevation of DA levels in the amygdala evoked by cocaine cues and thus effectively attenuate conditioned cocaine-seeking responses.

Another mechanism that may underlie the preferential effects of LY379268 on conditioned reinstatement compared with acute cocaine reinforcement involves altered glutamate function associated with cocaine exposure and withdrawal. Rats allowed to self-administer cocaine for 10-15 d show diminished activity of the cystine-glutamate antiporter after 3 weeks of withdrawal, a neuroadaptive change that may result in lower basal levels of glutamate in the Nac (Baker et al., 2003). Rats in the cocaine reinstatement group had more exposure to cocaine compared with the self-administration group ( 1 month vs 2 weeks) and, in addition, were subjected to a 1 week withdrawal period that was not imposed on rats in the cocaine self-administration group. It is possible, therefore, that basal glutamate levels may have been lower in rats of the cocaine reinstatement group than in rats tested for the effects of LY379268 on cocaine self-administration. As a result, LY379268 may have been effective in attenuating cocaine reinstatement at lower doses (i.e., in rats with already reduced glutamate function) than those required to interfere with cocaine self-administration (i.e., in rats with presumably higher glutamatergic tone).

\section{Effects on primary reinforcement by cocaine versus conventional reinforcers}

LY379268 reduced cocaine self-administration at the highest dose but failed to alter the reinforcing effects of SCM. This differential effect of mGlu2/3 activation may reflect the presumed existence of separate neural circuits mediating the rewarding effects of cocaine versus conventional reinforcers. There is evidence that distinct populations of Nac neurons differentially process information about cocaine versus natural rewards (Carelli et al., 2000; Carelli and Wondolowski, 2003). Neurons in the Nac receive input from many cortical and subcortical areas such as the prefrontal cortex and basolateral amygdala; therefore, selective activation of subpopulations of neurons in the Nac that process information about cocaine possibly occur because these neurons receive different afferent input than Nac neurons that encode information about natural rewards. The possibility that the effects of these distinct afferents are differentially modulated by mGlu $2 / 3$ receptors may provide one tentative explanation for the differential effect of LY379268 on cocaine versus SCM reward. Future research is needed to clarify this issue.

\section{Effects on reinstatement by stimuli conditioned to cocaine versus conventional reinforcers}

The data suggest that LY379268 is more effective at reversing reinstatement induced by stimuli conditioned to cocaine as opposed to SCM. As with the differential effect of LY379268 on primary reinforcement by cocaine and SCM, this finding may point toward the existence of separate neural circuits mediating the effects of stimuli conditioned to cocaine versus conventional reinforcers.

An alternative interpretation is that rats in the cocaine condition may have been more sensitive to the effects of LY379268 than the rats of the SCM group because of cocaine-induced neural adaptations. The history of cocaine exposure followed by extinction and abstinence may have altered glutamatergic neurotransmission (Xi et al., 2002), possibly conveying greater sensitivity to the effects of LY379268 in these animals compared with the cocaine-naive SCM group. Although repeated cocaine treatment alters $\mathrm{mGluR} 2 / 3$ protein levels and phosphorylation and thereby reduces the function of these receptors in the Nac (Xi et al., 2002), 
it cannot be ruled out that self-administration of cocaine may lead to different neuroadaptive changes in group II mGluR function or that changes in brain regions other than the Nac result in increased sensitivity to the effects of LY379268. Clarification of these issues will remain for future work.

In conclusion, several lines of evidence implicate group II mGluRs as potential pharmacotherapeutic targets for drug abuse intervention and, in particular, relapse prevention (Kim and Vezina, 2002; Xi et al., 2002). Consistent with this hypothesis, LY379268 selectively attenuated the rewarding effects of cocaine as opposed to those of a potent conventional reinforcer and antagonized conditioned reinstatement, an animal analog of relapse, produced by a stimulus conditioned to cocaine with greater potency than that produced by a stimulus conditioned to a nondrug reinforcer. Additionally, the results suggest that activation of group II mGluRs interferes more effectively with conditioned reinstatement by cocaine cues compared with the acute reinforcing effects of cocaine. Little information exists, to date, on pharmacological agents that selectively modify conditioned cocaine reinstatement versus cocaine self-administration, or the motivating effects of drug cues as opposed to stimuli conditioned to conventional reinforcers. Overall, the results reveal a possibly specific role for group II mGluRs in conditioned cocaine-seeking behavior and identify these receptors as a possible novel target for anti-relapse medications. What remains to be determined, once selective ligands for mGlu2 and mGlu3 receptors become available, is whether selective activation of either of these receptor subtypes would reveal a specific role for mGlu2 or mGlu3 receptors in conditioned reinstatement of cocaine-seeking relative to the primary reinforcing effects of the drug.

\section{References}

Baker DA, McFarland K, Lake RW, Shen H, Tang X, Toda S, Kalivas PW (2003) Neuroadaptations in cystine-glutamate exchange underlie cocaine relapse. Nat Neurosci 6:743-749.

Berke JD, Hyman SE (2000) Addiction, dopamine, and the molecular mechanisms of memory. Neuron 25:515-532.

Bond A, Jones NM, Hicks CA, Whiffin GM, Ward MA, O'Neill MF, Kingston AE, Monn JA, Ornstein PL, Schoepp DD, Lodge D, O’Neill MJ (2000) Neuroprotective effects of LY379268, a selective mGlu2/3 receptor agonist: investigations into possible mechanism of action in vivo. J Pharmacol Exp Ther 294:800-809.

Caine SB, Koob GF (1993) Modulation of cocaine self-administration in the rat through D-3 dopamine receptors. Science 260:1814-1816.

Carelli RM, Wondolowski J (2003) Selective encoding of cocaine versus natural rewards by nucleus accumbens neurons is not related to chronic drug exposure. J Neurosci 23:11214-11223.

Carelli RM, Ijames SG, Crumling AJ (2000) Evidence that separate neural circuits in the nucleus accumbens encode cocaine versus "natural" (water and food) reward. J Neurosci 20:4255-4266.

Cartmell J, Monn JA, Schoepp DD (1999) The metabotropic glutamate 2/3 receptor agonists LY354740 and LY379268 selectively attenuate phencyclidine versus D-amphetamine motor behaviors in rats. J Pharmacol Exp Ther 291:161-170.

Cartmell J, Monn JA, Schoepp DD (2000a) The mGlu(2/3) receptor agonist
LY379268 selectively blocks amphetamine ambulations and rearing. Eur J Pharmacol 400:221-224.

Cartmell J, Monn JA, Schoepp DD (2000b) Attenuation of specific PCPevoked behaviors by the potent $m$ Glu2/3 receptor agonist, LY379268, and comparison with the atypical antipsychotic, clozapine. Psychopharmacology (Berl) 148:423-429.

Clark M, Johnson BG, Wright RA, Monn JA, Schoepp DD (2002) Effects of the mGlu2/3 receptor agonist LY379268 on motor activity in phencyclidine-sensitized rats. Pharmacol Biochem Behav 73:339-346.

Cornish JL, Duffy P, Kalivas PW (1999) A role for nucleus accumbens glutamate transmission in the relapse to cocaine-seeking behavior. Neuroscience 93:1359-1367.

Helton DR, Tizzano JP, Monn JA, Schoepp DD, Kallman MJ (1997) LY354740: a metabotropic glutamate receptor agonist which ameliorates symptoms of nicotine withdrawal in rats. Neuropharmacology 36:1511-1516.

Helton DR, Tizzano JP, Monn JA, Schoepp DD, Kallman MJ (1998) Anxiolytic and side-effect profile of LY354740: a potent, highly selective, orally active agonist for group II metabotropic glutamate receptors. J Pharmacol Exp Ther 284:651-660.

Hotsenpiller G, Giorgetti M, Wolf ME (2001) Alterations in behaviour and glutamate transmission following presentation of stimuli previously associated with cocaine exposure. Eur J Neurosci 14:1843-1855.

Hurd YL, McGregor A, Ponten M (1997) In vivo amygdala dopamine levels modulate cocaine self-administration behaviour in the rat: D1 dopamine receptor involvement. Eur J Neurosci 9:2541-2548.

Ito R, Dalley JW, Howes SR, Robbins TW, Everitt BJ (2000) Dissociation in conditioned dopamine release in the nucleus accumbens core and shell in response to cocaine cues and during cocaine-seeking behavior in rats. J Neurosci 20:7489-7495.

Kim JH, Vezina P (2002) The mGlu2/3 receptor agonist LY379268 blocks the expression of locomotor sensitization by amphetamine. Pharmacol Biochem Behav 73:333-337.

Konieczny J, Ossowska K, Wolfarth S, Pilc A (1998) LY354740, a group II metabotropic glutamate receptor agonist with potential antiparkinsonian properties in rats. Naunyn Schmiedebergs Arch Pharmacol 358:500-502.

Martin-Fardon R, Ciccocioppo R, Dayas CV, Weiss F (2003) Comparison of neural activation induced by stimuli conditioned to cocaine versus a conventional reinforcer. Soc Neurosci Abstr 29:854.16.

Schoepp DD (2001) Unveiling the functions of presynaptic metabotropic glutamate receptors in the central nervous system. J Pharmacol Exp Ther 299:12-20.

Ungless MA, Whistler JL, Malenka RC, Bonci A (2001) Single cocaine exposure in vivo induces long-term potentiation in dopamine neurons. Nature 411:583-587.

Weiss F, Maldonado-Vlaar CS, Parsons LH, Kerr TM, Smith DL, Ben-Shahar O (2000) Control of cocaine-seeking behavior by drug-associated stimuli in rats: effects on recovery of extinguished operant-responding and extracellular dopamine levels in amygdala and nucleus accumbens. Proc Natl Acad Sci USA 97:4321-4326.

Weiss F, Martin-Fardon R, Ciccocioppo R, Kerr TM, Smith DL, Ben-Shahar O (2001) Enduring resistance to extinction of cocaine-seeking behavior induced by drug-related cues. Neuropsychopharmacology 25:361-372.

Wigmore MA, Lacey MG (1998) Metabotropic glutamate receptors depress glutamate-mediated synaptic input to rat midbrain dopamine neurones in vitro. Br J Pharmacol 123:667-674.

Wolf ME (1998) The role of excitatory amino acids in behavioral sensitization to psychomotor stimulants. Prog Neurobiol 54:679-720.

Xi ZX, Ramamoorthy S, Baker D, Shen H, Samuvel DJ, Kalivas PW (2002) Modulation of group II metabotropic glutamate receptor signaling by chronic cocaine. J Pharmacol Exp Ther 303:608-615. 